\title{
What is the Level of Asthma Knowledge in Middle Tennessee School Teachers? What is the Effect of Demographic Factors on Teacher Asthma Knowledge?
}

Stephen Carey $^{\star, 1}$ and Robert Cochrum ${ }^{2}$

${ }^{1}$ Department of Respiratory Care \& Health Information, Tennessee State University, 3500 John A. Merritt Boulevard, Nashville, TN 37209, USA

${ }^{2}$ Department of Human Performance and Sport Sciences, Tennessee State University, 3500 John A. Merritt Boulevard, Nashville, TN 37209 , USA

\section{Abstract}

Background: Asthma represents a potential threat to students when the school nurse or trained personnel are not available. When teachers need to assist asthmatic students, they need to have a sufficient level of knowledge to be effective until medical help arrives. This study used a sample of convenience to examine the level of teacher asthma knowledge for educators in Middle Tennessee and the effects of four demographic factors on their understanding of asthma using a sample of convenience.

Methods: Teachers completed a 13-question online survey $(\mathrm{n}=218)$ which evaluated their knowledge of asthma and the effects of demographic factors such as gender, school level taught, teachers' own asthma status, and educational attainment on knowledge of asthma.

Results: Teachers scored positively on the overall assessment of asthma knowledge with a mean score of correctness was 78\% (Likert 3.90). This is above the asthma knowledge efficacy threshold set at $70 \%$ (Likert 3.50) by an expert panel. In the demographic analysis, only teachers with a history of asthma had demonstrated a higher level of asthma knowledge $(M=4.09)$ as compared to teachers without asthma $(M=3.87)$. Other demographic factors such as gender, educational attainment, or school grade taught had no effect on asthma knowledge.

Conclusions: Teachers and educators held a level of asthma knowledge which was above the knowledge level threshold (Likert > 3.5). Teachers with a history of asthma held a higher overall knowledge of asthma than non-asthmatic teachers. No other demographic factors yielded a statistically significant effect. It is recommended public school systems regularly evaluate teacher asthma knowledge to ensure teachers are well prepared to assist students in an asthma emergency.

\section{Introduction}

Asthma is the leading chronic illness of students in our school systems [1]. This disease is characterized by a "chronic inflammatory disorder of the airways in which many cells and cellular elements play a role" [2]. Asthma triggers initiate a cascade of events that produce inflammation and narrowing of airways with an overproduction of mucus. 3 Cases of severe asthma are associated with more harmful long-term symptoms [4-6]. The consequences of this chronic illness can be severe with 111 children aged 5 to 14 dying between 2001 and 2003 [7].

School nurses may be unavailable on certain days of the week while covering more than one school in a district. The National Association of School Nurses report that not all schools have a full time school nurse and report, "approximately $35 \%$ of schools have a full time nurse, $40 \%$ of schools have a part time nurse, and $25 \%$ of schools report no nurse at all" [8]. Asthmatic students face an immediate danger when they have an asthma attack at school. When schools lack a school nurse, the risk level is compounded. Researchers find that the management of the student's asthma falls directly upon the classroom teacher [9].

The teacher's ability to help a student in respiratory distress may be especially important for school districts which lack a school nurse or have a part time nurse. Teacher knowledge of asthma should include an understanding the role of asthma triggers, the signs and symptoms of asthma, and steps to safely manage this condition $[10,11]$.

In an evaluation of asthma training at teacher colleges and universities, research finds teachers typically have little training about student asthma at the undergraduate or graduate levels of education

\section{Publication History:}

Received: September 01, 2020

Accepted: September 28, 2020

Published: September 30, 2020

\section{Keywords:}

Asthma knowledge, Demographic factors, Airway emergency with some teachers reporting no asthma training took place [12]. Teachers are not sufficiently prepared to help students avoid asthmatic triggers or manage asthmatic attacks [13]. Indeed, Goveia et al. found $55 \%$ of the teaching staff reported helping an asthmatic student with medication "regardless of asthma training" [14]. This presents a unique potentially dangerous set of parameters when the school nurse is not present and teachers without adequate training are obligated to assist asthmatic students in an airway emergency.

\section{Materials and Method}

The Maury County Public School System (MCPSS) is a Tennessee school system with 20 schools, 11, 040 students, 313 teachers on staff, and 223 unlicensed personnel with administrative offices located in Columbia, Tennessee. The participants in this study were teachers with varying levels of experience and education from elementary, middle, and high school levels in the MCPSS. The present study also included school staff with a high school diploma or general equivalency diploma (GED) who were employed in the district. Each teacher or educator participated based on an informed and voluntary

"Corresponding Author: Dr Stephen Carey, Department of Respiratory Care \& Health Information, Tennessee State University, 3500 John A. Merritt Boulevard, Nashville, TN 37209, USA; E-mail: stcarey@tnstate.edu

Citation: Carey S, Cochrum R (2020) What is the Level of Asthma Knowledge in Middle Tennessee School Teachers? What is the Effect of Demographic Factors on Teacher Asthma Knowledge? Int J Clin Res Trials 5: 151. doi: https://doi. org/10.15344/2456-8007/2020/151

Copyright: (C) 2020 Carey et al. This is an open-access article distributed under the terms of the Creative Commons Attribution License, which permits unrestricted use, distribution, and reproduction in any medium, provided the original author and source are credited. 
Citation: Carey S, Cochrum R (2020) What is the Level of Asthma Knowledge in Middle Tennessee School Teachers? What is the Effect of Demographic Factors on Teacher Asthma Knowledge? Int J Clin Res Trials 5: 151. doi: https://doi.org/10.15344/2456-8007/2020/151

Page 2 of 6

basis after giving informed consent. To qualify for the study, teachers and school staff were chosen based on their class assignments from Pre-kindergarten to high school.

School staffs were chosen by the district office based on staff contact with students. For simplification, teachers and educational staff are referred to as "teachers" or "educators" in this study. Asthma training previously conducted in the MCPSS system consisted of occasional asthma workshops and emailed information. A regular asthma training program did not exist at the time of this research. Teachers in the MCPSS system are required to obtain CPR training from the American Heart Association (Basic Life Support). The results of the MCPSS study will be used to develop more in-depth asthma training for teachers and staff.

The Teachers' Asthma Knowledge and Perception Survey (TAKPS) were chosen to measure the results for the present study (Table 1). The TAKPS is a 13-question survey utilized to measure teacher asthma knowledge in the State of Georgia $(n=593)$ by researchers NeuharthPritchett (2009) [15]. Survey results were completed online and anonymously submitted. On each survey question, a mean accuracy score was calculated and compared to the knowledge threshold score $(\mu>.70)$. The Cronbach's alpha is used to measure the reliability and consistency of the research questionnaire expressed in the scale of 0 to 1.0 with an acceptable score of .70 to .90 percent [16]. The TAKPS survey demonstrates a good internal consistency and reliability with a Cronbach's Alpha score of 0.84 .

The present study measured the asthma knowledge of teachers and reviewed the influence of 4 key demographic factors on teachers' asthma knowledge including the teachers' own asthma status, educational attainment, school level, and gender. In order to establish the level of teacher asthma knowledge, a committee of experts reviewed the asthma knowledge contained in the survey questions and established a score of $70 \%$ or higher (Likert $>3.5$ ) as a threshold or minimum level of understanding.

An independent sample t-test was conducted to test the independent asthma knowledge associated with each question. Calculated mean levels were determined to test the mean score of correctness against the minimum threshold score (Likert $3.5>$ ). A One-Way Analysis of Variance (ANOVA) and chi-square was performed on demographic categories related to "teacher's educational attainment" and "teachers school level taught”.

\section{Results and Discussion}

The survey was offered to 313 professional educators and 223 non-licensed personnel in an online format. In responding to this survey, 218 educators indicated their willingness to participate in this research. The sample primarily consisted of females ( $\mathrm{n}=188,86.24 \%)$, where males $(\mathrm{n}=30,13.76 \%)$ accounted for a smaller proportion of the sample (Table 2).

\begin{tabular}{|l|l|l|}
\hline Gender of MCPSS Participants \\
\hline Gender & $\mathrm{n}$ & $\%$ \\
\hline Female & 188 & 86.24 \\
\hline Male & 30 & 13.76 \\
\hline Total & 218 & 100.00 \\
\hline
\end{tabular}

Table 2: Summarizes the gender of the MCPSS sample. The sample included more female educators than males.

The majority of the respondents held a master's degree or higher ( $\mathrm{n}$ $=130,59.63 \%)$. The second largest group by educational attainment held a bachelor's degree $(n=76,34.86 \%)$. Educators with a high school diploma or general education diploma (GED) $(n=12,5.5 \%)$ were also included in this data since they are also active with students (Table 3 ).

\begin{tabular}{|l|l|l|}
\hline Educational Attainment & $\mathrm{n}$ & $\%$ \\
\hline High School Diploma/GED & 12 & 5.5 \\
\hline Bachelor's Degree & 76 & 34.9 \\
\hline Master's Degree or higher & 130 & 59.6 \\
\hline Total & 218 & 100.00 \\
\hline
\end{tabular}

Table 3: Summarizes the educational attainment of survey respondents. More school personnel with a bachelor's degree and master's degree were represented than school personnel with a high school diploma of General Equivalency Diploma (GED).

Educators in the Pre-Kindergarten/Elementary level $(\mathrm{n}=104$, $47.71 \%$ ) represented a larger group than those educators in the other two school levels of Middle school $(\mathrm{n}=61,27.98 \%)$ and High school ( $\mathrm{n}=53,24.31 \%)$ (Table 4$)$. Staff roles of all educators in the sample included teachers, coaches/assistant coaches, principals/

\begin{tabular}{|l|l|}
\hline 1. & Asthma is a common disease among children in the United States. \\
\hline 2. & Asthma is an emotional or psychological illness. \\
\hline 3. & The way that parents raise their children can causeasthma. \\
\hline 4. & Asthma episodes may cause breathing problems, butthese episodes are rarely dangerous. \\
\hline 5. & Asthma episodes usually occur without warning. \\
\hline 6. & Many different things can bring on an asthma attack. \\
\hline 7. & Asthma cannot be cured, but it can be controlled. \\
\hline 8. & There are different types of medicine to control asthma. \\
\hline 9. & People with asthma have no way to monitor how well their lungs are functioning. \\
\hline 10. & Both children and adults can have asthma. \\
\hline 11. & People can outgrow asthma. \\
\hline 12. & Tobacco smoke can make an asthma episode worse. \\
\hline 13. & People with asthma should not exercise. \\
Table 1: Asthma Knowledge Survey Questions.
\end{tabular}


Citation: Carey S, Cochrum R (2020) What is the Level of Asthma Knowledge in Middle Tennessee School Teachers? What is the Effect of Demographic Factors on Teacher Asthma Knowledge? Int J Clin Res Trials 5: 151. doi: https://doi.org/10.15344/2456-8007/2020/151

Page 3 of 6

assistant principals, guidance counselors, administrative, and other staff members who are in contact with students.

\begin{tabular}{|l|l|l|}
\hline Educational Setting for MCPSS Participants \\
\hline Educational Setting & $\mathrm{n}$ & $\%$ \\
\hline PreK/Elementary & 104 & 47.70 \\
\hline Middle & 61 & 28.00 \\
\hline High & 53 & 24.09 \\
\hline Total & 218 & 100.00 \\
\hline
\end{tabular}

Table 4: Summarizes the educational setting of survey respondents. More school personnel from Pre-K and Elementary were represented than school personnel from middle school or high school.

Educators with asthma accounted for $14.22 \%$ of the sample population (Table 5). More female teachers had asthma $(\mathrm{n}=28)$ as compared to male teachers with asthma $(n=3)$ (Table 6).

Overall Asthma Status for Maury County Public School System Participants

\begin{tabular}{|l|l|l|}
\hline Asthma Status & $\mathrm{n}$ & $\%$ \\
\hline Teachers with Asthma & 31 & 14.22 \\
\hline Teachers without Asthma & 187 & 85.78 \\
\hline Total & 218 & 100.00 \\
\hline
\end{tabular}

Table 5: Summarizes the asthma status of participants.

\begin{tabular}{|l|l|l|l|l|l|l|}
\hline \multicolumn{2}{|c|}{ Asthma Status for MCPSS Participants by Gender } \\
\hline \multirow{2}{*}{} & \multicolumn{2}{|c|}{ Without Asthma } & \multicolumn{2}{|c|}{ With Asthma } & \multicolumn{2}{c|}{ Total } \\
\cline { 2 - 8 } & $\mathrm{n}$ & Group $\%$ & $\mathrm{n}$ & Group $\%$ & $\mathrm{n}$ & $\%$ \\
\hline Male & 28 & 12.84 & 3 & 1.38 & 31 & 14.22 \\
\hline Female & 159 & 72.94 & 28 & 12.84 & 187 & 85.78 \\
\hline Total & 187 & 85.78 & 31 & 14.22 & 218 & 100.00 \\
\hline
\end{tabular}

Table 6: Summarizes the asthma status by gender. The sample included more female asthmatics than male asthmatics.
The overall mean score of teacher asthma knowledge was calculated at 3.90 (Table 7). Additional analysis was conducted utilizing an independent sample t-test. According to this assessment, asthma knowledge was adequate in this sample, $t(217)=18.32, \mathrm{p}<.001$. Teachers' asthma knowledge was above the mean score previously established of 3.5.

An independent sample t-test was used to assess the effect of asthma status on asthma knowledge score. Teachers with asthma $(M=4.09)$ scored higher than teachers without asthma $(M=3.87)$, $t(216)=-3.68, \mathrm{p}<.001$. Educators with asthma scored statistically significant higher on asthma knowledge survey than teachers without asthma (Table 8). Teachers who self-identified having asthma scored statistically significantly higher on only seven questions $(2,6,7,8,9$, 10 , and 13) out of the thirteen questions on the survey.

There were some unique results noted in this demographic. Educators with and without asthma both scored below the asthma knowledge threshold (Likert 3.5, $M=70 \%$ ) on "knowledge of the causes of asthma, asthma warning, and outgrowing asthma" (questions 3, 5, and 11).

Asthma knowledge was measured and compared by an educators' educational attainment utilizing a One-Way Analysis of Variance (ANOVA) and chi-square (Table 9). No statistically significant difference was found when comparing the knowledge of teachers with a graduate degree and teachers with an undergraduate degree. Teachers' asthma knowledge by school level taught (Pre-K, Middle, and High) was assessed utilizing an ANOVA and chi-square (Table 10). No statistically significant difference was

found when comparing the knowledge of teachers at elementary versus middle schools or when comparing the knowledge of teachers at elementary schools with teachers at high schools. Teacher's asthma knowledge based on gender was assessed using an independent sample t-test. No statistically significant difference was found when assessing the effect of gender (male, female) on teacher asthma knowledge (Table 11).

\begin{tabular}{|c|c|c|c|}
\hline Item $(n=218)$ & $M$ & $S D$ & $\%$ \\
\hline 1. Asthma is a common disease among children in the United States. & 4.14 & 0.622 & 82.8 \\
\hline 2. Asthma is an emotional or psychological illness. & 3.96 & 0.905 & 79.2 \\
\hline 3. The way that parents raise their children can cause asthma. & $3.28^{*}$ & 1.116 & 65.6 \\
\hline $\begin{array}{l}\text { 4. Asthma episodes may cause breathing problems, but these episodes } \\
\text { are rarely dangerous. }\end{array}$ & 4.18 & 0.866 & 83.6 \\
\hline 5. Asthma episodes usually occur without warning. & $2.85^{\star *}$ & 0.926 & 57.0 \\
\hline 6. Many different things can bring on an asthma attack. & 4.27 & 0.504 & 85.4 \\
\hline 7. Asthma cannot be cured, but it can be controlled. & 4.02 & 0.689 & 80.4 \\
\hline 8. There are different types of medicine to control asthma. & 4.20 & 0.537 & 84.0 \\
\hline $\begin{array}{l}\text { 9. People with asthma have no way to monitor how well their lungs } \\
\text { are functioning. }\end{array}$ & 3.77 & 0.751 & 75.4 \\
\hline 10. Both children and adults can have asthma. & 4.50 & 0.510 & 90.0 \\
\hline 11. People can outgrow asthma. & $2.75^{\star *}$ & 0.938 & 55.0 \\
\hline 12. Tobacco smoke can make an asthma episode worse. & 4.47 & 0.561 & 89.4 \\
\hline 13. People with asthma should not exercise. & 4.28 & 0.551 & 85.6 \\
\hline Mean Score of Correctness & 3.90 & - & 78.0 \\
\hline
\end{tabular}

Table 7: Overall Asthma Knowledge of MCPSS Teachers by Asthma Knowledge Item.

** $<3.5, M \leq 70 \%$. 
Citation: Carey S, Cochrum R (2020) What is the Level of Asthma Knowledge in Middle Tennessee School Teachers? What is the Effect of Demographic Factors on Teacher Asthma Knowledge? Int J Clin Res Trials 5: 151. doi: https://doi.org/10.15344/2456-8007/2020/151

Page 4 of 6

\begin{tabular}{|c|c|c|c|c|c|c|c|c|}
\hline Asthma Status & With & ut $(n=$ & 187) & Wit & $(n=31$ & & & 16) \\
\hline Asthma Knowledge Items & $M$ & $S D$ & $\%$ & $M$ & $S D$ & $\%$ & $t$ & $p$ \\
\hline 1. Asthma is a common disease among children in the United States. & 4.12 & 0.623 & 82 & 4.23 & 0.617 & 85 & -0.85 & 0.395 \\
\hline 2. Asthma is an emotional or psychological illness. & 3.91 & 0.912 & 78 & 4.26 & 0.815 & 85 & -1.98 & $0.05^{\star}$ \\
\hline 3. The way that parents raise their children can cause asthma. & $3.29^{*}$ & 1.114 & 66 & $3.23^{* *}$ & 1.146 & 65 & 0.315 & 0.753 \\
\hline 4. Asthma episodes may cause breathing problems, but these episodes are rarely dangerous. & 4.17 & 0.825 & 83 & 4.26 & 1.094 & 85 & -0.52 & 0.606 \\
\hline 5. Asthma episodes usually occur without warning. & $2.89^{*}$ & 0.918 & 58 & $2.61^{\star *}$ & 0.955 & 52 & 1.535 & 0.126 \\
\hline 6. Many different things can bring on an asthma attack. & 4.21 & 0.480 & 84 & 4.65 & 0.486 & 93 & -4.68 & $0.001^{*}$ \\
\hline 7. Asthma cannot be cured, but it can be controlled. & 3.96 & 0.691 & 79 & 4.39 & 0.558 & 88 & -3.25 & $0.001^{*}$ \\
\hline 8. There are different types of medicine to control asthma. & 4.15 & 0.528 & 83 & 4.48 & 0.508 & 90 & -3.28 & $0.001^{*}$ \\
\hline 9. People with asthma have no way to monitor how well their lungs are functioning. & 3.70 & 0.708 & 74 & 4.19 & 0.873 & 84 & -3.47 & $0.001^{\star}$ \\
\hline 10. Both children and adults can have asthma. & 4.47 & 0.511 & 89 & 4.74 & 0.445 & 95 & -2.84 & $0.005^{*}$ \\
\hline 11. People can outgrow asthma. & $2.72^{*}$ & 0.909 & 54 & $2.90^{* *}$ & 1.106 & 58 & -0.996 & 0.320 \\
\hline 12. Tobacco smoke can make an asthma episode worse. & 4.44 & 0.559 & 89 & 4.61 & 0.558 & 92 & -1.56 & 0.120 \\
\hline 13. People with asthma should not exercise. & 4.22 & 0.542 & 84 & 4.61 & 0.495 & 92 & -3.74 & $0.001^{*}$ \\
\hline Average Mean Score & 3.87 & - & 77 & 4.09 & - & 82 & - & - \\
\hline
\end{tabular}

Table 8: Asthma Knowledge of MCPSS Teachers and Educators by Asthma Status.

${ }^{*}<3.5, M=70 \% ;{ }^{*} p<.05$.

\begin{tabular}{|c|c|c|c|c|c|}
\hline Educational Attainment & $\begin{array}{l}\text { High School/ } \\
\text { GED }(n=12)\end{array}$ & $\begin{array}{l}\text { Bachelor's } \\
(n=76)\end{array}$ & $\begin{array}{l}\text { Master's+ } \\
(n=130)\end{array}$ & $\begin{array}{l}\text { Chi Sq } \\
(d f=2\end{array}$ & \\
\hline Asthma Knowledge Items & $M$ rank & $M$ rank & $M$ rank & $X^{2}$ & $p$ \\
\hline 1. Asthma is a common disease among children in the United States. & 110.50 & 112.00 & 107.92 & 0.335 & 0.846 \\
\hline 2. Asthma is an emotional or psychological illness. & 90.70 & 119.40 & 105.47 & 3.970 & 0.137 \\
\hline 3. The way that parents raise their children can cause asthma. & 152.58 & 100.50 & 110.79 & 7.770 & $.021^{\star}$ \\
\hline 4. Asthma episodes may cause breathing problems, but these episodes are rarely dangerous. & 128.50 & 109.50 & 107.73 & 1.482 & 0.477 \\
\hline 5. Asthma episodes usually occur without warning. & 125.75 & 104.60 & 110.87 & 1.550 & 0.461 \\
\hline 6. Many different things can bring on an asthma attack. & 91.30 & 115.03 & 107.95 & 2.492 & 0.288 \\
\hline 7. Asthma cannot be cured, but it can be controlled. & 80.80 & 112.89 & 110.17 & 3.861 & 0.145 \\
\hline 8. There are different types of medicine to control asthma. & 84.90 & 114.14 & 109.06 & 3.326 & 0.190 \\
\hline 9. People with asthma have no way to monitor how well their lungs are functioning. & 84.70 & 111.49 & 110.63 & 2.360 & 0.307 \\
\hline 10. Both children and adults can have asthma. & 99.70 & 113.03 & 108.34 & 0.759 & 0.684 \\
\hline 11. People can outgrow asthma. & 78.70 & 101.75 & 116.87 & 6.488 & $0.039^{*}$ \\
\hline 12. Tobacco smoke can make an asthma episode worse. & 80.30 & 111.20 & 111.20 & 3.515 & 0.172 \\
\hline 13. People with asthma should not exercise. & 87.20 & 109.45 & 111.59 & 2.306 & 0.316 \\
\hline Average Mean Rank & 99.66 & 110.39 & 109.89 & & \\
\hline
\end{tabular}

Table 9: Asthma Knowledge of Teachers and Educators by Educational Attainment.

${ }^{*} p<.05$.

\begin{tabular}{|c|c|c|c|c|c|}
\hline & $\begin{array}{l}\text { PreK/Elementary } \\
(n=104)\end{array}$ & $\begin{array}{l}\text { Middle }(n \\
=61)\end{array}$ & $\begin{array}{l}\text { High } \\
(n=53) \\
\end{array}$ & \multicolumn{2}{|c|}{$\begin{array}{l}\text { Chi Square } \\
(d f=2)\end{array}$} \\
\hline Asthma Knowledge Items & $M$ rank & $M$ rank & $M$ rank & $X^{2}$ & $p$ \\
\hline 1. Asthma is a common disease among children in the United States. & 112.35 & 109.81 & 103.55 & 1.104 & 0.576 \\
\hline 2. Asthma is an emotional or psychological illness. & 105.75 & 108.32 & 118.23 & 1.609 & 0.447 \\
\hline 3. The way that parents raise their children can cause asthma. & 108.78 & 117.10 & 102.17 & 1.742 & 0.419 \\
\hline 4. Asthma episodes may cause breathing problems, but these episodes are rarely dangerous. & 113.19 & 104.54 & 107.96 & 0.952 & 0.621 \\
\hline 5. Asthma episodes usually occur without warning. & 108.47 & 112.60 & 107.95 & 0.243 & 0.885 \\
\hline 6. Many different things can bring on an asthma attack. & 101.80 & 121.70 & 110.56 & 5.769 & $0.04^{*}$ \\
\hline 7. Asthma cannot be cured, but it can be controlled. & 105.55 & 114.31 & 111.72 & 1.180 & 0.554 \\
\hline 8. There are different types of medicine to control asthma. & 103.59 & 117.13 & 112.31 & 2.830 & 0.243 \\
\hline 9. People with asthma have no way to monitor how well their lungs are functioning. & 110.24 & 117.56 & 98.77 & 3.034 & 0.219 \\
\hline 10. Both children and adults can have asthma. & 107.71 & 111.42 & 110.81 & 0.217 & 0.897 \\
\hline 11. People can outgrow asthma. & 119.04 & 100.25 & 101.43 & 5.113 & 0.078 \\
\hline 12. Tobacco smoke can make an asthma episode worse. & 109.64 & 106.93 & 112.18 & 0.256 & 0.880 \\
\hline 13. People with asthma should not exercise. & 104.13 & 118.93 & 109.18 & 2.979 & 0.226 \\
\hline Average Mean Rank & 108.48 & 112.35 & 108.22 & & \\
\hline
\end{tabular}

Table 10: Asthma Knowledge of Teachers and Educators by School Level.

${ }^{*} p<.05$. 
Citation: Carey S, Cochrum R (2020) What is the Level of Asthma Knowledge in Middle Tennessee School Teachers? What is the Effect of Demographic Factors on Teacher Asthma Knowledge? Int J Clin Res Trials 5: 151. doi: https://doi.org/10.15344/2456-8007/2020/151

Page 5 of 6

\begin{tabular}{|c|c|c|c|c|c|c|c|c|}
\hline \multirow[t]{2}{*}{ Asthma Knowledge Items } & \multicolumn{3}{|c|}{ Female $(n=188)$} & \multicolumn{3}{|c|}{ Male $(n=30)$} & \multicolumn{2}{|c|}{$t(216)$} \\
\hline & $M$ & $S D$ & $\%$ & $M$ & $S D$ & $\%$ & $t$ & $p$ \\
\hline 1. Asthma is a common disease among children in the United States. & 4.14 & 0.608 & 83 & 4.10 & 0.712 & 82 & 0.356 & 0.722 \\
\hline 2. Asthma is an emotional or psychological illness. & 4.02 & 0.874 & 80 & $3.63^{* *}$ & 1.033 & 73 & $2.169^{* *}$ & 0.031 \\
\hline 3. The way that parents raise their children can cause asthma. & $3.35^{\star *}$ & 1.129 & 67 & $2.90^{* *}$ & 0.96 & 58 & $2.046^{* *}$ & 0.042 \\
\hline 4. Asthma episodes may cause breathing problems, but these episodes are rarely dangerous. & 4.21 & 0.856 & 84 & 4.03 & 0.928 & 81 & 1.023 & 0.307 \\
\hline 5. Asthma episodes usually occur without warning. & $2.82^{* *}$ & 0.901 & 56 & $3.03^{* *}$ & 1.066 & 61 & -1.18 & 0.240 \\
\hline 6. Many different things can bring on an asthma attack. & 4.28 & 0.505 & 86 & 4.23 & 0.504 & 85 & 0.436 & 0.663 \\
\hline 7. Asthma cannot be cured, but it can be controlled. & 4.00 & 0.686 & 80 & 4.17 & 0.699 & 83 & -1.23 & 0.219 \\
\hline 8. There are different types of medicine to control asthma. & 4.20 & 0.536 & 84 & 4.20 & 0.551 & 84 & -0.03 & 0.976 \\
\hline 9. People with asthma have no way to monitor how well their lungs are functioning. & 3.78 & 0.755 & 76 & 3.73 & 0.740 & 75 & 0.292 & 0.770 \\
\hline 10. Both children and adults can have asthma. & 4.51 & 0.512 & 90 & 4.47 & 0.507 & 89 & 0.438 & 0.662 \\
\hline 11. People can outgrow asthma. & $2.72^{* *}$ & 0.958 & 54 & $2.90^{* *}$ & 0.803 & 58 & -0.96 & 0.340 \\
\hline 12. Tobacco smoke can make an asthma episode worse. & 4.47 & 0.561 & 89 & 4.47 & 0.571 & 89 & 0.013 & 0.990 \\
\hline 13. People with asthma should not exercise. & 4.26 & 0.548 & 85 & 4.40 & 0.563 & 88 & -1.29 & 0.199 \\
\hline Average Mean Score & 3.90 & - & 78 & 3.87 & - & 77 & - & - \\
\hline
\end{tabular}

Table 11: Asthma Knowledge of MCPSS Teachers and Educators by Gender.

${ }^{\star *}<3.5, M=70 \%$; ${ }^{*} p<.05$

\section{Conclusion}

The purpose of this study is to assess the current level of asthma knowledge of educators in the Maury County Public School System (MCPSS) and determine what effect demographic factors (teacher's own asthma status, educational attainment, and school level taught, and gender) have on the teacher's asthma knowledge.

The present asthma knowledge study held a generally positive outlook for MCPSS educators $(\mathrm{n}=218)$. The overall group score $(\mathrm{M}=3.90)$ exceeded the predetermined score $(\mathrm{M}=3.50)$ indicating a minimally needed asthma knowledge by teachers and educators When assessing the demographic factors (teacher's own asthma status, educational attainment, school level taught, and gender), it was found that only the teacher's own asthma status positively affected asthma knowledge $(\mathrm{M}=4.09)$. Other demographic factors such as: educationalattainment, school level taught, and gender) made no statistically significant effect on asthma knowledge. This finding agrees with previous research from Neuharth-Pritchett et al. (2009) which also found teachers with asthma had a greater level of asthma knowledge than teachers without asthma [17]

MCPSS teachers had asthma knowledge scores above the preestablished threshold for asthma knowledge efficacy; scores were derived based on a brief survey. Soo and colleagues (2013) point out that a lack of standardized asthma knowledge questionnaires complicates the evaluation of knowledge surveys [18]. Asthma knowledge should be further examined with a more comprehensive, uniform survey instrument which will allow more effective cross comparisons.

When school nurses are not present, teachers must fill a critical role for assisting asthmatic students in breathing easier and potentially saving a student's life. To ensure educators are effective when working with asthmatic students, school districts must include an appropriate amount of educational resources during in-service education workshops, staff meetings, and other areas. School systems need to measure both the level of educator knowledge as well as the current level of school resources and institutional capability dedicated to helping manage this chronic illness.
Ensuring asthma educational interventions are consistent with the needs of asthmatic students requires an approach which is grounded in regular asthma education and uniform knowledge assessment. The levels of support and assistance schools provide to improve educators' knowledge of asthma play a critical role in establishing the abilities of educators to assist asthmatic students. School districts need to consistently monitor the resources and knowledge teachers have for asthma.

The current study demonstrated encouraging results. Educators at MCPSS had an overall group score $(\mathrm{M}=3.90)$ which exceeded the previously minimally established Likert score of 3.5.In reviewing the demographic analysis, teachers who had a medical history of asthma had a better knowledge of asthma than teachers who did not have asthma. Demographic factors such as educational level, school level taught, or gender had no statistically significant effect on teacher asthma knowledge.

The role of the teacher or educator does not stop at the classroom door. Students with asthma count on teachers and educators to assist them, especially when school nurses are unavailable. Teachers and educators at all levels must have a greater understanding and awareness of this disease. Our commitment to students with asthma begins with the ability to measure teacher asthma knowledge and ends with delivering more effective care when students experience a breathing emergency during an asthma attack.

\section{Competing Interests}

The authors declare that they have no competing interests.

\section{References}

1. Center for Disease Control and Prevention (2010) Summary health statistics for U.S. children: national health survey 2008. DHHS publication.

2. Global Initiative for Asthma (2010) Global strategy for asthma management and prevention.

3. Bloom B, Dey AN (2004) Summary health statistics for U.S. children: National Health Interview Survey.

4. Martinez FD (2003) Toward asthma prevention - Does all that really matters happen before we learn to read? N Engl J Med 349: 1473-1475. 
Citation: Carey S, Cochrum R (2020) What is the Level of Asthma Knowledge in Middle Tennessee School Teachers? What is the Effect of Demographic Factors on Teacher Asthma Knowledge? Int J Clin Res Trials 5: 151. doi: https://doi.org/10.15344/2456-8007/2020/151

Page 6 of 6

5. Panettieri RA, Covar R, Grant E, Hillyer EV, Bacharier L, et al. (2008) Natural history of asthma: Persistence versus progression - does the beginning predict the end? J Allergy Clin Immunol 121: 607-613.

6. Reed CE (2006) The natural history of asthma. J Allergy Clin Immunol 118 543-548.

7. Mooreman JE, Rudd RA, Johnson CA, King M, Minor P, et al. (2007) National surveillance for asthma - United States 1980-2004. MMWR Surveill Summ 56: 1-54.

8. Nikpour J, Hassmiller S (2017) A full-time nurse for every school: A call to action to make it happen. NASN Sch Nurse 32: 290-293.

9. Rodehorst TK (2003) Rural elementary school teachers' intent to manage children with asthma symptoms. Pediatr Nurs 29: 184-194.

10. Goveia MG, Shaikh N (2005) Asthma-related environmental practices and asthma awareness in California childcare. Pediatric Asthma, Allergy, and Immunology 18: 12-24.

11. Bruzzese JM, Unikel LH, Evans D, Bornstein L, Surrence K, et al. (2010) Asthma knowledge and asthma management behavior in urban elementary school teachers. J Asthma 47: 185-191.

12. Neuharth-Pritchett $S$, Getch YQ (2001) Asthma and school teachers: The status of teacher preparedness and training. J Sch Nurs 424: 323-328.

13. Alley $S$, Cicutto $L(2009)$ Exploring the supportiveness and preparedness of child care settings for children with asthma. J Asthma 46: 512-516.

14. Goveia MG, Shaikh N, Windham G, Bembom O, Feldman K, et al. (2005) Asthma-related environmental practices and asthma awareness in California childcare centers. Pediatric Asthma, Allergy, and Immunology 18: 13-21.

15. Neuharth-Pritchett S, Getch YQ (2009) Teacher characteristics and knowledge of asthma. Public Health Nurse 26: 124-133.

16. Tavakol M, Dennick R (2011) Making Sense of Cronbach's Alpha. Int J Med Educ 2: 53-55.

17. Neuharth-Pritchett S, Getch Y, Schilling E (2009) Asthma and the Public School Teacher: A Two State Study. Pediatr Allergy Immunol Pulmonol 32: 109-116.

18. Soo Y, Saini B, Moles M (2003) Can asthma education improve the treatment of acute asthma exacerbation in young children? J Paediatr Child Health 49: 927-934. 